\title{
Thermographic Diagnostic of Different Skin Reactions After Intradermal Testing
}

\section{Evgeni Stanev*, Maria Dencheva and Georgi Nikolov}

Faculty of Dental Medicine - Image and Oral Diagnostics, Medical University, Sofia, Bulgaria

*Corresponding Author: Evgeni Stanev, Faculty of Dental Medicine - Image and Oral Diagnostics, Medical University, Sofia, Bulgaria.
Received: November 09, 2020

Published: December 08, 2020

(c) All rights are reserved by Evgeni Stanev., et al.

\begin{abstract}
We present a case of an intradermal allergy test involving positive and negative reactions to allergens. The standard reading is supplemented by thermal imaging and calculation of an indicator related to the change in temperature due to allergic reactions in the examined skin areas (dT). The results show that the temperature reading can complement the standard test, and the dT indicator can be used to distinguish positive from negative reactions.
\end{abstract}

Keywords: Allergy; Skin Reactions; Papule

\section{Introduction}

Intradermal allergic reactions are used to study sensitization to various allergens. Their standard reading includes two indicators of allergic inflammation: papule (tumor) and redness (rubor). With the help of innovative methods, other indicators can be studied, such as warming (calor) [1]. Such a method is thermovisiography. It allows capturing the subject with an infrared camera and subsequent analysis using specialized software. We present a clinical case of a man in which thermovisiographic reading is used as an auxiliary method.

\section{Clinical Case}

The patient, a 22-year-old man, was referred for allergic testing to the NCIPD. On examination, he reported a cough and difficulty breathing of unknown origin for 4 months. Most often the symptoms appear when visiting rooms with poor ventilation and dust. When taking antihistamines, the symptoms go away. He also suffers from seasonal allergic rhinitis, in connection with which he takes an antihistamine (Xyzal) in the spring. Based on these data, a working diagnosis was made - allergy to house dust and indoor household allergens and an intradermal test was performed.

\section{Material}

The following commercial diagnostic allergens (Bul Bio NCIPD, Sofia Bulgaria) were tested:

A1. House dust $1000 \mathrm{BU} / \mathrm{ml}$ (Area 1); A2. Down and feathers $1000 \mathrm{BU} / \mathrm{ml}$ (Area 2); EI. Mixed mold allergen $1000 \mathrm{BU} / \mathrm{ml}$ (Area 3); E7. Candida albicans $1000 \mathrm{BU} / \mathrm{ml}$ (Area 4); A3 Dog hair and dandruff $1000 \mathrm{BU} / \mathrm{ml}$ (Area 5); A5 Cat hair and dandruff $1000 \mathrm{BU} /$ $\mathrm{ml}$ (Area 6); negative control - Coca solution (Area 7). The test was conducted at NCIPD (Bulgaria), Allergy Department. A FLIR T620 thermal imaging camera was used for thermal imaging.

\section{Methods}

$0.02 \mathrm{ml}$ of each of the allergens and the negative control is injected subcutaneously into the skin of the forearm after cleansing with alcohol. After 20 minutes the result was reported. The standard reading included the size of the papule and erythema in $\mathrm{mm}$ of each of the reactions. Reactions with papules and erythema over $7 \mathrm{~mm}$ are considered positive.

Thermal imaging included reading the average skin temperature for each of the reactions and dT values. Some research teams study the difference in skin temperature before and after the test [2]. This approach does not take into account the change in skin temperature due to mechanical trauma from the needle. The different reactivity of the skin in patients does not allow setting limit values for different strength reactions. In addition, during the test, the hand stays still, away from the body, which leads to cooling of the skin temperature, regardless of the allergy test [3].

The dT indicator is used successfully to distinguish positive from negative intradermal allergic reactions [4]. The values are calculated by subtracting the temperature of the negative control from the reaction temperature.

$\mathrm{dT}=\mathrm{T}$ (allergic reaction) $-\mathrm{T}$ (neg. control) 


\begin{tabular}{|l|c|c|c|c|}
\hline & Papula & Erythema & $\begin{array}{c}\text { Tempera- } \\
\text { ture }\end{array}$ & dT \\
\hline Ar 1 (House dust) & 10 & 18 & 34.3 & 1.3 \\
\hline $\begin{array}{l}\text { Ar 2 (Down and } \\
\text { feathers) }\end{array}$ & 7 & 7 & 34.1 & 1.1 \\
\hline $\begin{array}{l}\text { Ar 3 (Group mold } \\
\text { allergen) }\end{array}$ & 7 & 7 & 34.3 & 1.3 \\
\hline $\begin{array}{l}\text { Ar 4 (Dog hair and } \\
\text { dandruff) }\end{array}$ & 0 & 0 & 33.6 & 0.6 \\
\hline $\begin{array}{l}\text { Ar 5 (Cat hair and } \\
\text { dandruff) }\end{array}$ & 0 & 0 & 33.4 & 0.4 \\
\hline $\begin{array}{l}\text { Ar 6 (Candida } \\
\text { albicans) }\end{array}$ & 0 & 0 & 32.9 & -0.1 \\
\hline Ar 7 (neg. control) & 0 & 0 & 33.0 & \\
\hline
\end{tabular}

Table 1: Results from standard and thermal evaluation.

Results from standard and thermal imaging:

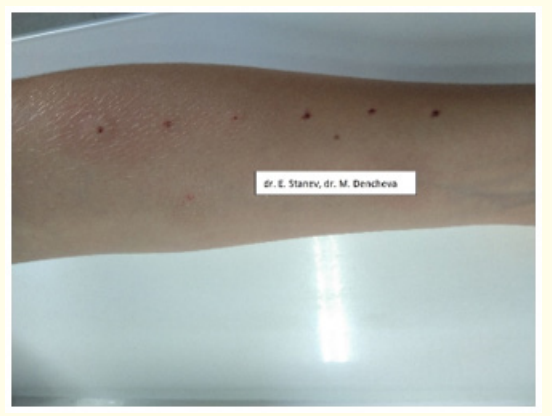

Figure 1: Picture of the forearm after the test.

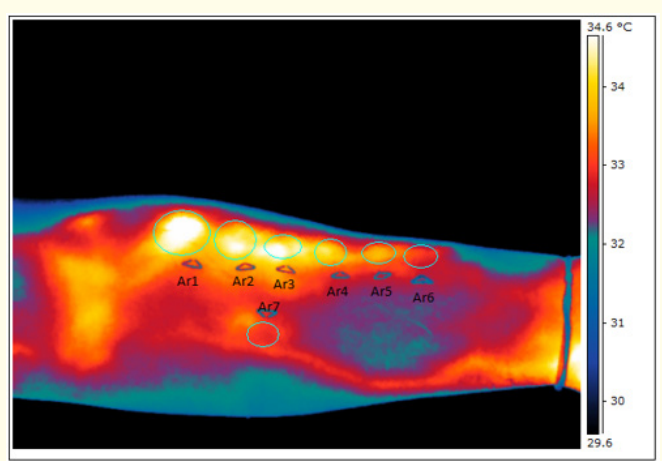

Figure 2: Thermal picture of the forearm after the test.

\section{Discussion}

The results of the standard reading show a very positive reaction to house dust with papules and erythema over $7 \mathrm{~mm}$. Two slightly positive reactions with papule size and erythema of $7 \mathrm{~mm}$ were observed for bird down and mold, respectively. The remaining reactions were reported as negative.

The results of the thermovisiographic examination show that the temperature of the skin areas is the highest in the strongly positive reaction, lower in the two weakly positive ones and the lowest in the area of the negative reactions and the negative control. To quantify the change in temperature due to the allergic reaction, the $d T$ index is examined. In the analysis of the studied indicator, the distinction of the different strength reactions is made by comparing their temperature with the temperature reported in the negative control. This allows to establish the difference in the heat of the skin, which occurs as a result of allergic inflammation, and other subjective factors influencing the inflammation (trauma from the needle puncture, individual skin reactivity) are excluded [4]. The thermal imaging image also shows the skin area where the temperature changes due to allergic inflammation. In positive reactions, there is an overlap of these areas.

\section{Conclusion}

Thermovision diagnostics can successfully supplement the standard reading in intradermal allergy tests. The method allows not only to distinguish positive from negative reactions, but also to compare between them. Using temperature indicators such as $\mathrm{dT}$, the severity of allergic inflammation in each of the allergens can be quantified. The method also allows visualization of the skin area that is involved in the reaction. When performing the test, the allergens need to be injected at a greater distance from each other so that the skin reactions do not overlap.

\section{Bibliography}

1. Bernstein I Leonard., et al. "Allergy diagnostic testing: an updated practice parameter". Annals of Allergy, Asthma and Immunology 100.3 (2008): S1-S148.

2. Koyama N., et al. "Computer-assisted infrared thermographic study of axon reflex induced by intradermal melittin". Pain 84 (2000): 133-139.

3. Stanev E., et al. "Thermographic examination of prick test reactions with local anesthetic". Journal of Thermal Analysis and Calorimetry 140.1 (2020): 225-231.

4. Stanev E. "Thermovisiography in skin-allergic tests - PhD thesis" (2020).

\section{Assets from publication with us}

- Prompt Acknowledgement after receiving the article

- Thorough Double blinded peer review

- Rapid Publication

- Issue of Publication Certificate

- High visibility of your Published work

Website: www.actascientific.com/

Submit Article: www.actascientific.com/submission.php Email us: editor@actascientific.com Contact us: +919182824667 